\title{
Invited Discussion on: Breast Reduction-33 Years Using a Single Central Block
}

\author{
Peter $\operatorname{Scott}^{1}{ }^{1}$
}

Received: 28 August 2019/Accepted: 5 September 2019/Published online: 1 October 2019

(C) Springer Science+Business Media, LLC, part of Springer Nature and International Society of Aesthetic Plastic Surgery 2019

Level of Evidence $V$ This journal requires that authors assign a level of evidence to each article. For a full description of these Evidence-Based Medicine ratings, please refer to the Table of Contents or the online Instructions to Authors www.springer.com/00266.

Breast reduction patients are amongst our most grateful patients, and most of them are prepared to trade very large, uncomfortable, pendulous breasts for the smaller size and better shape result. The trade-off in breast surgery is always shape versus scars and in this case, the ability to breast feed and preserve nipple sensation. The authors are to be complimented on their very detailed explanation of their surgical technique and honest presentation of their complication rate.

The basis of surgery is a sound knowledge of anatomy, and the authors mention Van Deventer (2008) and I would like to add to their reference list: two further publications by Van Deventer [1] and Van Deventer and Graewe [2]. These articles revisit the blood supply of the breast with careful anatomical dissections and with attention to the variations in blood supply that may contribute to necrosis of breast tissue. Of particular importance is retaining the medial vertical ligament of Würinger as this will usually preserve the second, third and fourth perforators of the internal thoracic artery.

Finally, no discussion of the various pedicles and techniques would be complete without including the superomedial pedicle, and by preserving the blood supply, one is able to utilise this in the type of surgeries where a free nipple graft would previously apply. The reader is referred

\footnotetext{
Peter Scott

peterscott@cinet.co.za

1 Morningside Clinic, Johannesburg, South Africa
}

to Landau and Hudson [3] for a good summary of this technique that was previously presented in this journal by Hauben [4].

My own personal preferred technique over a similar time period has evolved into the use of a superior pedicle retaining the medial vertical ligament of Würinger or a superomedial pedicle. These have avoided the need for free nipple grafts in my practice and have reduced the incidence of fat necrosis and in the case of the superior pedicle retained in many cases the ability to breast feed.

\section{Compliance with Ethical Standards}

Conflict of interest The author declares that he has no conflicts of interest to disclose.

Ethical Approval This article does not contain any studies with human participants or animals performed by any of the authors.

Informed Consent For this type of study, informed consent is not required.

\section{References}

1. Van Deventer PV (2010) Enhancing pedicle safety in mastopexy and breast reduction procedures: the posteroinferomedial pedicle, retaining the medial vertical ligament of Würinger. Plast Reconstr Surg 126:786-793

2. Van Deventer PV, Graewe FR (2016) The blood supply of the breast revisited. Plast Reconstr Surg 137(5):1388-1397

3. Landau A, Hudson D (2008) Choosing the superomedial pedicle for reduction mammaplasty in gigantomastia. Plast Reconstr Surg 121:735-739

4. Hauben DJ (1984) Experience and refinements with the superomedial dermal pedicle for nipple-areolar transposition in reduction mammoplasty. Aesthet Plast Surg 8:189

Publisher's Note Springer Nature remains neutral with regard to jurisdictional claims in published maps and institutional affiliations. 